\title{
Intercomparison of satellite-based and model-based rainfall analyses
}

\author{
Martina Kästner ${ }^{1}$, Francesca Torricella ${ }^{2} \&$ Silvio Davolio ${ }^{2}$ \\ ${ }^{1}$ Deutsches Zentrum für Luft- und Raumfahrt (DLR), Institut für Physik der Atmosphäre \\ Oberpfaffenhofen, D-82234 Wessling, Germany \\ ${ }^{2}$ National Research Council (CNR), Institute of Atmospheric Sciences and Climate (ISAC) \\ Via Gobetti 101, I-40129 Bologna, Italy \\ Email: martina.kaestner@dlr.de
}

Four satellite rain estimations based on microwave ( $M W)$, infrared (IR) or combined $M W-I R$ techniques are compared with the BOlogna Limited Area Model (BOLAM) rain forecast for a severe weather event (8-13 November 2001) over the western Mediterranean Sea.

Two of the investigated multi-channel $M W$ rainfall algorithms use data from the Tropical Rainfall Measuring Mission (TRMM). The Frequency Difference Algorithm relies on data from the TRMM Microwave Imager (TMI) and the other one combines data from the Precipitation Radar (PR) with those from the nine-channel radiometer TMI, called PR Adjusted TMI Estimations of Rainfall (PATER) algorithm. The pure IR Rain Estimator uses geostationary IR METEOSAT data and the combined Naval Research Laboratory algorithm uses both $M W$ data from low orbiting satellites and IR data from the geostationary orbit.

Validation results, computed over a common grid, which is independent of the different field of view sizes of the applied data sets, indicate that there is generally a better performance for heavy rain $\left(>6 \mathrm{~mm} \mathrm{~h}^{-1}\right)$ than for light rain $\left(<1 \mathrm{~mm} \mathrm{~h}^{-1}\right)$. Both $M W$ algorithms perform rather similarly, although $P A T E R$ shows some rain detection problems due to thick aerosol loads originating from the desert. The $B O L A M$ model presents a good agreement with the $M W$ and only a minor location error of a heavy rain area was detected. Both $I R$-based algorithms have problems in identifying the correct rainy areas compared to $M W$. Overall, the results suggest that there are advantages in combining both techniques the well-known rain physics of the $M W$ channels with the high temporal resolution of IR algorithms - to retrieve precipitation from satellite data.

Keywords: satellite, rain retrieval, mesoscale model, METEOSAT, BOLAM

Received 27 October 2005, revised 8 March 2006

\section{Introduction}

The atmosphere obtains three-quarters of its heat energy from the release of latent heat by precipitation (Hartman 1994; Kummerow et al. 1998). Differences in large-scale rainfall pattern affect the entire global circulation. However, the scarcity of conventional rain gauge measurements, particularly over water bodies, prevents adequate sampling of the precipitation field for global applications. Therefore, satellite data are a valuable source of information on clouds and rainfall (Todd \& Bailey 1995).

Various climate models predict a decrease of precipitation in the future over many parts of the subtropics, particularly in winter (Bolle 2003). Therefore, it is essential to have not only climatological data from land but also from over the seas. Unfortunately, rainfall, unlike other meteorological parameters, is highly variable both spatially and temporally. Remote areas not covered by conventional observation networks can now be continuously monitored by low orbiting and geostationary satellites. The first satellite rain retrievals in both the infrared (IR) and the microwave (MW) spectra date back to the 1970s (Barrett 1970; Barrett \& Martin 1981; Kidder \& Vonder Haar 1995). Recently, within the EURAINSAT project (Levizzani et al. 2001, 2006; Levizzani 2003) different approaches have been used, such as the algorithms of Turk et al. (2000a), Bauer et al. (2000, 2001), Bauer (2001), Levizzani et al. (2001), 
Tapiador (2002) and Kidd et al. (2003), besides other workers such as Grose et al. (2002) and Oh et al. (2002).

Passive microwave (PMW) precipitation algorithms are directly linked to the 3-D structure of the precipitating system. They use measurements from different sensors on different satellites, including the Special Sensor Microwave/Imager (SSM/I) on board the Defense Meteorological Satellite Program (DMSP), the Tropical Rainfall Measurement Mission (TRMM) MW Imager (TMI) and the Precipitation Radar (PR) on board the TRMM, and the Advanced MW Sounding Unit (AMSU) on board the National Oceanic and Atmospheric Administration (NOAA) satellites. PMW techniques perform much better over the oceans than over land, because the emission of water is very low compared to land surfaces in the $\mathrm{GHz}$ range. The usually unknown radiative emission of land can be estimated to some extent on a global scale (Prigent 2006a, 2006b). The PMW techniques are directly related to the hydrometeors through scattering and emission, but the poor spatial resolution and time coverage of MW sensors on board low Earth-orbiting platforms prevent the tracking of developing severe storms.

The MW data used in this article rely on TRMM measurements. Since the area of the tropics is mainly ocean, precipitation there can only be measured satisfactorily from space. In 1997 the TRMM satellite (Kummerow et al. 1998), a joint US (National Aeronautics and Space Administration (NASA)) and Japanese (National Space Development Agency (NASDA)) project, was successfully launched carrying five instruments. For the first time a satellite carried both active and passive MW sensors for measuring precipitation. Since the aim of TRMM is to measure rainfall in the tropics, a low inclination orbit $\left(35^{\circ}\right)$ with respect to the equatorial plane was selected. After a boost into a 400-km orbit in August 2001, the conical swaths of TMI, about $850 \mathrm{~km}$ wide, now cover the southern Mediterranean Sea up to latitude $39^{\circ} \mathrm{N}$. The low orbit compared to the SSM/I platform enable a much better resolution of the TMI data, which are a very valuable source for studying the so-called Algerian flood in November 2001. TRMM is still in orbit and has emerged as one of the most successful missions to monitor and study rainfall from space.

While the daily evolution of precipitation is not easily obtained from TRMM data, IR-based techniques from geostationary satellites have been widely used due to the high revisit period. At present, only measurements taken from geostationary platforms have sufficient spatial resolution (a few square $\mathrm{km}$ ), temporal resolution (15-30 $\mathrm{min}$ ) and spatial coverage to follow the rapid variations of precipitation fields properly. Moreover, the long history and the robust technology of instruments on geostationary platforms enable the reanalysis of historical events and guarantee a timely and reliable release of calibrated data. Visible and IR measurements, however, only give indirect information on the precipitation field, as they are limited to the uppermost cloud layer. Their uncertainties are thus relevant per se since the precipitating hydrometeors do not interact directly with the photons collected aloft by space-borne instruments at these wavelengths. Several methods, called blended techniques, have been developed that 'calibrate' IR brightness temperature $\left(\mathrm{T}_{\mathrm{B}}\right)$ data collected from geostationary sensors by using the more physically based rain estimates derived from PMW instruments, radar and raingauge measurements.

Validation is a process of assessing by independent means the uncertainties of the data products derived from the system outputs. The rain characteristics vary with different climate regimes, and thus any developed method has to be validated against appropriate in situ measurements that are taken over the region of interest. Over the past years several intercomparisons within the Precipitation Intercomparison Projects (PIP) and the satellite precipitation Algorithm Intercomparison Programmes (AIP) (Ebert et al. 1996; Ebert \& Manton 1998; Adler et al. 2001) have favoured the development and use of global satellite precipitation products. The main result was that the PMW estimates produced the best instantaneous results and the IR-based estimates provided the best long-term estimates. A crosscomparison of rainfall data sets from the low orbiting TRMM satellite and the gauge data of the Global Precipitation Climate Project (GPCP) are described in Adler et al. (2002). One of the most challenging tasks of validation-intercomparison is to find a common structure that enables the combination of data sets in different temporal or spatial resolutions.

In the present study a fine-scale regional intercomparison of rain intensities was performed derived from PMW and/or IR-based algorithms and the mesoscale Bologna limited-area model (BOLAM). The selected region is the south-western Mediterranean Sea in a common grid for one episode, namely the Algerian flood in early November 2001.

Following the description of the severe weather event in Section 2, the descriptions of the data follow in Section 3 and the method of analysis and information on the algorithms used is given in Section 4. In Section 5 , the results of the rainfall comparison are discussed, and finally in Section 6, an assessment of the results is presented.

\section{Meteorological situation}

Different rain algorithms are applied to a severe weather episode that affected the south-western Mediterranean area between 8 and 13 November 2001. It was characterised by heavy rainfall and flooding over Algeria and wind storms especially over the Balearic Islands (Kästner \& Erbertseder 2002; Pinori et al. 2002; Thomas et al. 2003; Tripoli et al. 2005). 


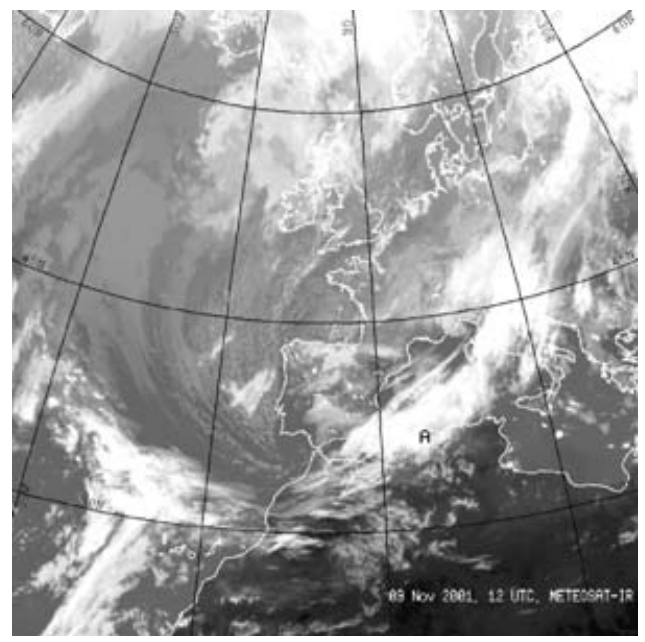

Figure 1. METEOSAT-7 IR image on 9 November 2001, 1200 UTC, $A=$ Algiers.

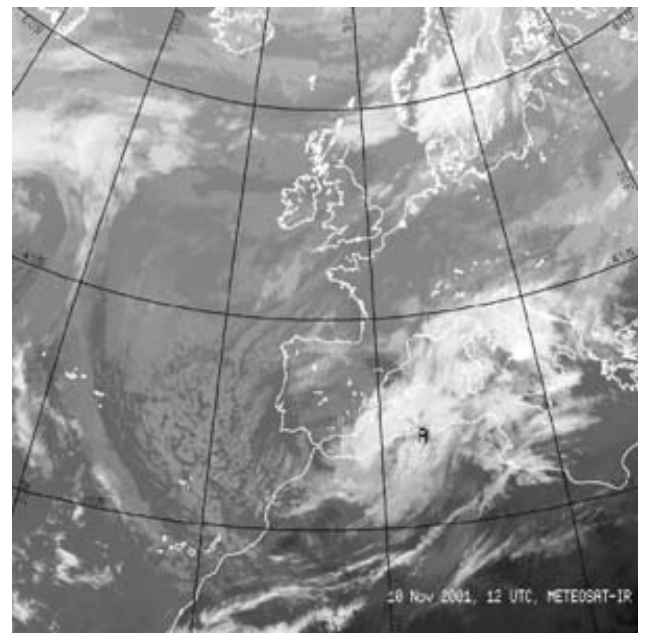

Figure 2. METEOSAT-7 IR image on 10 November 2001, 1200 UTC, $A=$ Algiers.

In the middle troposphere, a cold trough, extending from northeast to southwest over the western Mediterranean Sea, developed on 9 November 2001 (Figure 1). It was associated with a pronounced tropopause fold and polar air advection towards the Iberian Peninsula. On the following day, favoured by the unstable baroclinic environment, an intense cyclone evolved rapidly over the Algerian coast and deepened, moving northward towards the Balearic Islands (Figure 2). Between 9 and 10 November Algeria was struck by a devastating flood, caused by a significant amount of precipitation, which caused more than 700 fatalities and massive material damage. The rainfall started in Algeria late on 9 November and ended the next day at about noon. Some $150 \mathrm{~mm}$ fell in 6 hours and almost $300 \mathrm{~mm}$ in less than 24 hours, locally. The METEOSAT-7 (data: European Organisation for the Exploitation of Meteorological Satellites (EUMETSAT)) IR images in Figures 1 to 3 show the cloud system associated with the cyclone, affecting the Algerian and Balearic coasts.
Satellite-based and model-based rainfall analyses

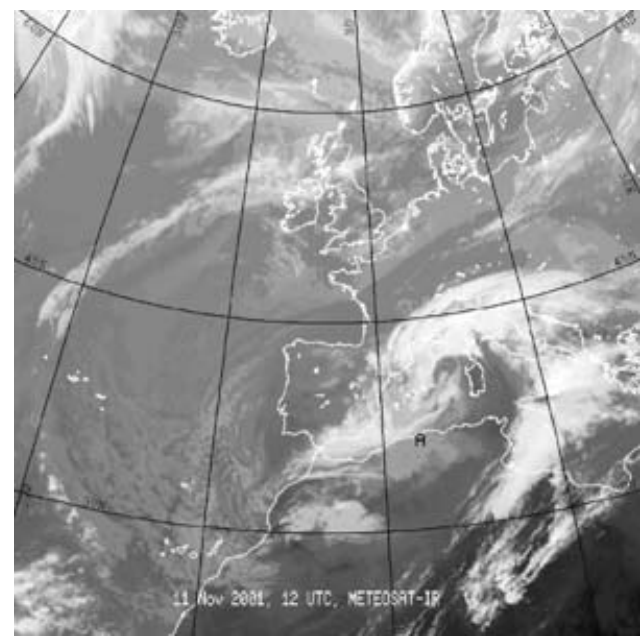

Figure 3. METEOSAT-7 IR image on 11 November 2001, 1200 UTC, $A=$ Algiers.

On 11 November, the cyclone reached its maximum intensity. Very warm continental tropical air, reaching values up to $18^{\circ} \mathrm{C}$ at $850 \mathrm{hPa}$, from the Sahara Desert mixed with Arctic cold air, close to $0^{\circ} \mathrm{C}$ at $850 \mathrm{hPa}$, on the east side of the cyclone. In this highly unstable air, a storm cyclogenesis with a core of tropical warm air developed (Figure 3), which is noteworthy because this is not usual at these latitudes (Tripoli et al. 2005). At high levels a trough evolved into a cut-off low. The strong pressure gradient over the Balearic Islands induced a severe wind storm $\left(150 \mathrm{~km} / \mathrm{h}^{-1}\right.$ winds), and heavy thunderstorms were reported. Rainfall in excess of $400 \mathrm{~mm}$ in less than 48 hours was observed between 10 and 12 November.

Two processes intensified the convective development which led to the flooding disaster in Algeria: (1) the cold Maritime Arctic air that crossed over the still warm Mediterranean Sea $\left(18^{\circ} \mathrm{C}\right)$ where it picked up moisture, destabilised, and met initially subtropical air; and (2) the strong surface winds blowing against the mountains $(>2300 \mathrm{~m})$ along the African coast that caused intense orographic rainfall.

\section{Data}

\section{I. Mesoscale BOLAM model}

The simulations were carried out with the hydrostatic model BOLAM (Buzzi et al. 2003). Model dynamics are based on primitive equations, with wind components $u$ and $v$, potential temperature $\theta$, specific humidity $q$ and surface pressure $p_{s}$ as dependent variables.

Within the 3-D model, the vertical coordinate is terrain following $(\sigma)$. The vertical discretisation between $\sigma$ levels is of the Lorenz type, with vertical velocity defined at levels intermediate between those where the prognostic variables are known. The horizontal discretisation uses geographical coordinates, with 
latitudinal rotation on an Arakawa C-grid. Secondorder horizontal and vertical differencing is employed. The model implements an original second-order, forward-backward advection scheme (Malguzzi \& Tartaglione 1999). A more detailed description of the dynamics and numerical schemes can be found in Davolio \& Buzzi (2004).

The water cycle for stratiform precipitation is described by means of five prognostic variables (cloud ice, cloud water, rain, snow, graupel), with a simplified approach similar to that proposed by Schultz (1995). Deep convection is parameterised using the KainFritsch (Kain \& Fritsch 1990) convective scheme, with some modifications, including those suggested by Spencer \& Stensrud (1998) to improve the effect of the downdraft. The surface and boundary layer scheme is based on the mixing length theory, with exchange coefficients computed as a function of the Richardson number, as in Louis et al. (1981). Surface processes are described by water and energy balances in a threelayer ground model. The radiation is computed with the application of the Geleyn scheme (Ritter \& Geleyn 1992).

The orography used in the simulations is derived from the interpolation and smoothing of the $1 \mathrm{~km}$ $\left(1 / 120^{\circ}\right)$ resolution Global Land 1-km Base Elevation (GLOBE) Digital Elevation Model of the National Geographical Data Center (NGDC). The initial and lateral boundary conditions were supplied by the European Centre for Medium-Range Weather Forecasts (ECMWF) 6-hourly analyses at $0.5^{\circ} \times 0.5^{\circ}$ resolution. Hybrid model-level data are directly interpolated on the limited area model grid. Snow cover, sea surface temperature, soil temperature and soil wetness are also derived from the analyses. The model was tested and favourably compared with many other mesoscale limited area models during the course of the COMPARE WMO (World Meteorological Organisation) Project (Georgelin et al. 2000).

All the simulations were performed using a grid of $170 \times 150$ points, with a horizontal resolution of about $22 \mathrm{~km}\left(0.2^{\circ}\right.$ in rotated coordinates $)$ and 38 vertical levels. The spacing between levels is variable, with the highest resolution in the boundary layer.

In order to produce 3-hourly accumulated rainfall at 0300,0600 and 0900 UTC, the simulations were initialised at 1200 UTC the day before. Model-generated precipitation at these times therefore corresponds to a $15 \mathrm{~h}, 18 \mathrm{~h}$ and $21 \mathrm{~h}$ forecast, respectively. Three forecasts were performed and rainfall data for 9-11 November 2001 were generated.

\subsection{Satellite related algorithms}

The TMI collects passive radiance information at 10.7, 19.4, 21.3, 37.0 and $85.5 \mathrm{GHz}$, having increasing ground spatial resolution from 70 to $6 \mathrm{~km}$. All the channels are horizontally $(\mathrm{h})$ and vertically $(\mathrm{v})$ polarised, except for the $21.3 \mathrm{GHz}$ channel, which is only vertically polarised. The adopted PMW algorithms are based on brightness temperatures $\left(\mathrm{T}_{\mathrm{B}}\right)$ derived from the radiances measured in the above-mentioned channels. The main information in the $11 \mathrm{GHz}$ channel comes from the ground while at higher frequencies the information comes from upper parts of the atmosphere under cloud-free conditions.

Figure 4 shows $\mathrm{T}_{\mathrm{B}}$ maps from three of nine TMI channels for one TRMM orbit over the study area. The brightness temperature maps at $19 \mathrm{GHz}$ (horizontal polarisation (a) and vertical polarisation (b)) reveal a considerable contrast between ocean and land owing to the different emissions of water and land. At this frequency the rainy bands appear to be warmer than the cloud-free water and they can clearly be detected north of Africa, while over land rain appears to be colder than the background due to the high MW emission of land. Both channels show similar $T_{B}$ values within the rainy areas (low polarisation), while the rain-free oceanic areas have considerably different $\mathrm{T}_{B} \mathrm{~S}$ due to reflection at the polarising ocean surface. This reflection indirectly depends on the wind velocity through the wave heights. Although the $85 \mathrm{GHz}$ channel (Figure 4c) has much better horizontal resolution than the others, the rainy areas are not easily outlined because the rain/norain contrast is much smaller. The $85 \mathrm{GHz}$ channel is influenced by scattering due to ice particles, which act to decrease the $T_{B}$ by increasing the probability that photons become scattered out of the beam before being detected. An example of this behaviour can be seen in Figure $4 \mathrm{c}$ where the two active convective cores west of Algiers and west of Sicily are characterised by $T_{B}$ values less than $190 \mathrm{~K}$.

The applied rain retrievals and rain data are now briefly described.

The IR Rain Estimator (IRE) is an operational rapid update purely IR-based algorithm to diagnose half-hourly near-surface rainfall. It is an empirical technique suited for acquisitions from geostationary satellites such as METEOSAT. It uses some relevant features of the cloud top evolution and structure as well as information from a numerical weather prediction model (F. Meneguzzo, private communication).

In the adopted blended technique (Turk et al. 2000a, 2000b), hereafter called the Naval Research Laboratory (NRL) technique, the original operational set-up of the software (global, automatic, real time, using a suite of PMW and IR observations) was adapted to the task of analysing test case studies. In the NRL technique, rain intensities derived from PMW measurements are used to create global, geo-located rain rate $(R R)$ and $T_{B}$ (brightness temperature) relationships that are renewed as soon as new co-located data are available from both geostationary and PMW instruments. The rain 
(a)

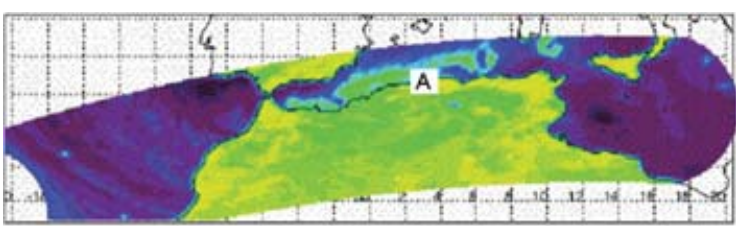

(b)

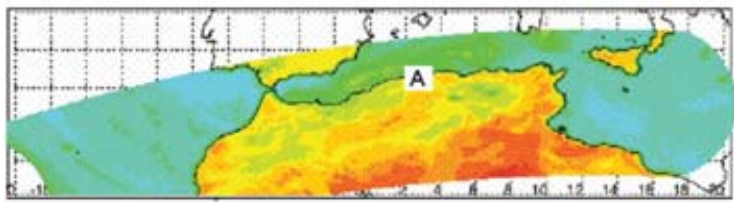

(c)

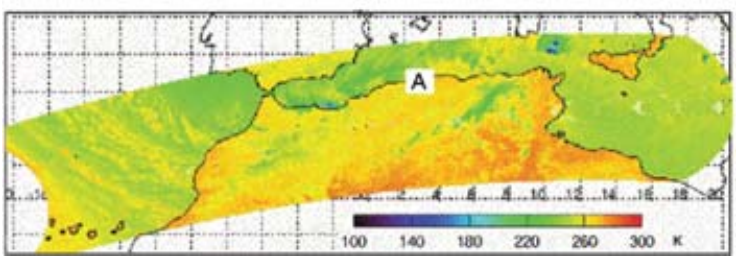

Figure 4. 10 November 2001, orbit time 0025 UTC. TMI brightness temperatures of (a) top: 19b; (b) mid: 19v; and (c) bottom: $85 v \mathrm{GHz}$ channels ( $v=$ vertical, $b=$ horizontal polarisation, A=Algiers).
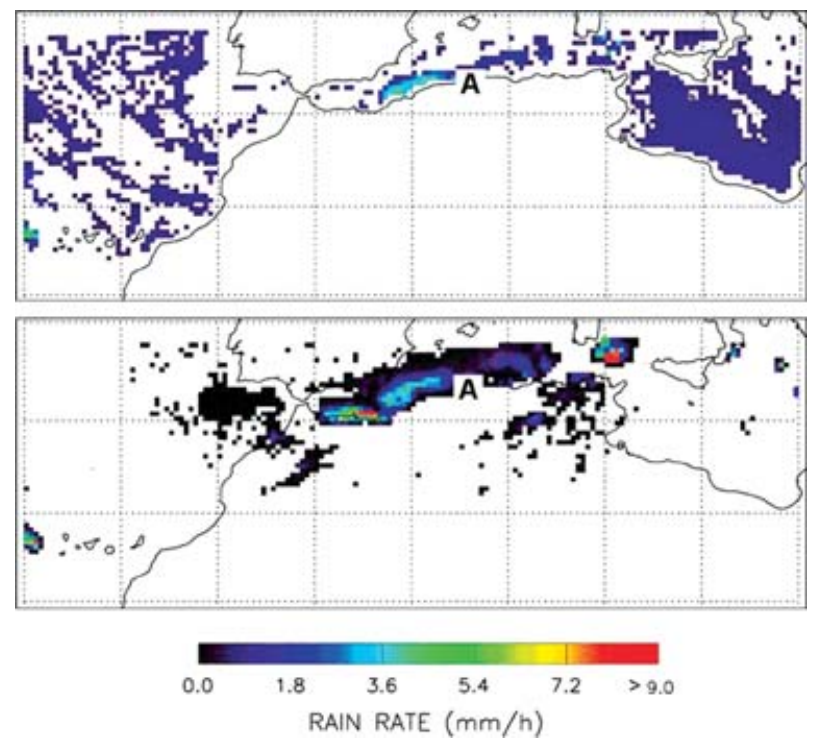

Figure 5. 10 November 2001, TMI orbit $22741+22742$, 00:25 + 02:10 UTC. A = Algiers, top: PATER, bottom: FDA $P M W$ algorithms.

rate can be derived, in principle, from any source, provided they are geo-located rain intensities measured in $\mathrm{mm} \mathrm{h}^{-1}$, and contain some useful information (orbit, date, start time, sensor, satellite). For the present work the rain rate estimates are derived from SSM/I data. From the brightness temperatures measured in seven polarised channels from 19.2 to $85.5 \mathrm{GHz}$, rain rates are derived by means of the NOAA-NESDIS (National Environmental Satellite, Data and Information Services) operational algorithm (Ferraro \& Marks 1995; Ferraro 1997). The NESDIS algorithm derives rain rates at the A-scan resolution of the SSM/I $(\sim 25 \mathrm{~km})$ by means of non-linear relationships involving the instrument channels (vertical and horizontal polarisation) that have

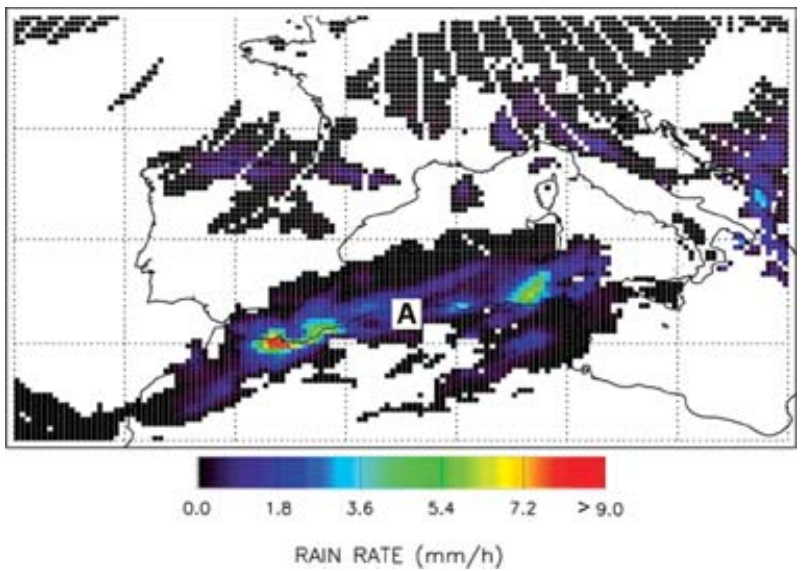

Figure 6. 10 November 2001, 0300 UTC. $A=$ Algiers, $B O L A M-$ model.

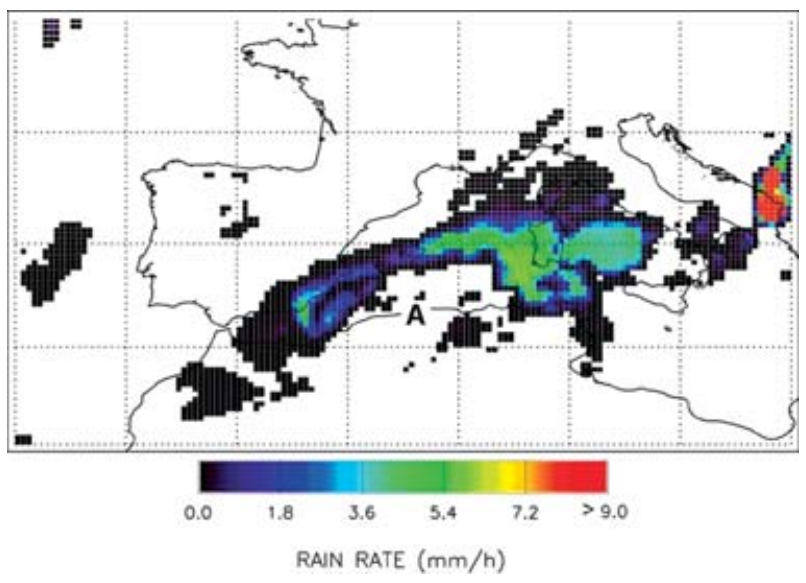

Figure 7. 10 November 2001, 0300 UTC. $A=$ Algiers, NRLcombined IR-MW algorithm.

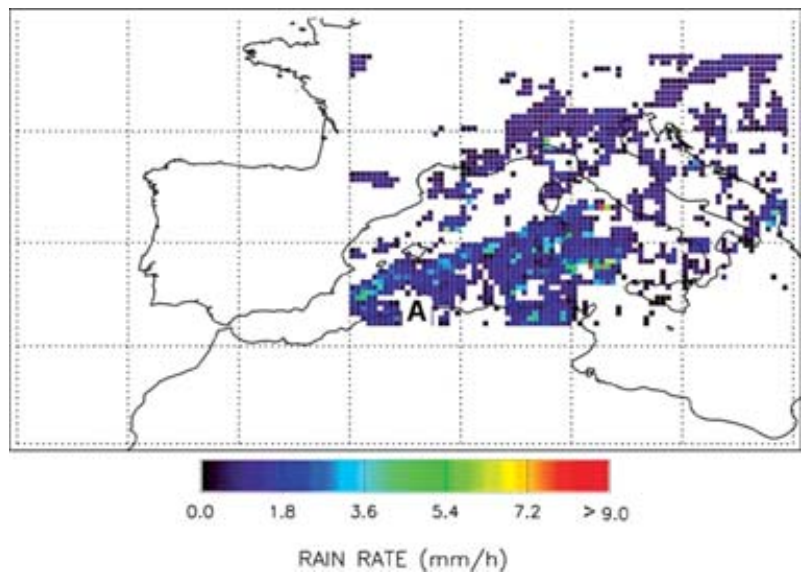

Figure 8. 10 November 2001, 0300 UTC. $A=$ Algiers, IREIR algorithm.

been calibrated using large sets of ground reference data collected by radar networks in different countries. The physical basis of such relationships are the scattering of MW radiation due to large ice particles above the freezing level occurring in precipitating clouds, and the emission from liquid water. This latter 
phenomenon can be sensed only above oceanic surfaces owing to the high and largely unknown emissivity of land surfaces in the MW spectral range. Relying on PMW measurements only (without need for a large input-database of physical properties) and on simple but well-founded relationships, this algorithm is very robust and lends itself to global applications. To calibrate IR measurements, the globe (or the study area) is subdivided into equally spaced boxes $\left(2.5^{\circ}\right.$ latitude $\times 2.5^{\circ}$ longitude $)$. For each box, space and time coincident IR and PMW measurements are reduced to the worse spatial resolution and then collected. The co-location process allows for time and space offsets $(15 \mathrm{~min}$ and $10 \mathrm{~km}$, respectively). In order to form a meaningful statistical ensemble, the method can look at older PMW orbit-IR slot intersections, until a certain $(75 \%)$ box coverage is reached and a minimum number of coincident observations are gathered for a $2.5^{\circ} \times 2.5^{\circ}$ region. By means of this set of rain rates and corresponding $T_{B}$, the rain rate- $T_{B}$ relationships are derived by applying a probability matching method (Calheiros \& Zawadzki 1987).

The Frequency Difference Algorithm (FDA) by Kidd described in Ebert (1996) uses the $19 \mathrm{v}$ and $19 \mathrm{~h} \mathrm{GHz}$ channels and relates them to the rain rate. This PMW satellite rain algorithm is operationally applied to TRMM as well as SSM/I orbit data over land and ocean.

The over-ocean satellite rainfall algorithm PR Adjusted TMI Estimations of Rainfall (PATER: Bauer et al. 2001) is a physical PMW algorithm developed for moderate and heavy rain intensities. A principal component analysis reduces the redundant information content of the nine TMI channels to only two empirical orthogonal functions. The retrieval database of forward simulations of TMI- $\mathrm{T}_{\mathrm{B}}$, is generated from several 3-D cloud models including hydrometeor profiles, the melting layer and different geometries (Bauer 2001). The algorithm has a stand-alone PMW component based on TMI brightness temperatures only, and an optional calibration with carefully co-located surface rain intensities retrieved from PR measurements (having a spatial resolution of about $5 \mathrm{~km}$ ), downscaled to the lower spatial resolution of the $11 \mathrm{GHz}$ channel of TMI $(\sim 50 \mathrm{~km})$. Since the swath of the coincident PR measurements is only about $215 \mathrm{~km}$, these high-resolution data are useful for calibration issues, provided that the PR data are bias free. However, recent comparison analysis of PR with ground-based radar data revealed an underestimation of the PR rain rates (Schumacher \& Houze 2000). Assumptions in the PATER retrieval imply a minimum rainfall rate of $1 \mathrm{~mm} \mathrm{~h}^{-1}$.

\section{Method of analysis}

In a pre-study, Kästner (2003) reported on rain rates from the experimental over-ocean PATER algorithm that were merged from three TRMM overpasses per day and then downscaled to a $1^{\circ} \times 1^{\circ}$ grid for a comparison with the independent $1^{\circ}$-daily Global Precipitation Climatology Centre (GPCC) data (Rudolf et al. 1996) at adjacent gauge locations at coasts or islands. The result was a correlation coefficient of 0.71 between the data sets, although the temporal data structure was different - merged instantaneous versus accumulated rain rates. This result was very encouraging because the best operational rain algorithm in the PIP-3 study (Adler et al. 2002) performed with a correlation of 0.75 . The false alarm rate (see below) indicated a sensitivity of the PATER algorithm to be about $0.7 \mathrm{~mm}$ $\mathrm{h}^{-1}$ at this $1^{\circ}$ resolution, which is equivalent to a liquid water content of $0.05 \mathrm{~g} \mathrm{~m}^{-3}$. In the cited intercomparison study, the use of a common area, period, grid and format was essential for combining data sets with different temporal and spatial resolutions that sometimes described different physical observables. All subsequent tasks such as calibration, sampling, or error analysis needed a common grid that allowed an equivalent evaluation.

For the joint effort of validating and comparing several rain algorithms developed and applied within the scope of the EURAINSAT project, the different data types were reassembled in a unique grid that provides an effective basis for comparing instantaneous and merged space measurements of different algorithms with a mesoscale forecast from the BOLAM model. Continuous and categorical statistics were used according to Ebert et al. (1996) and Ebert \& Manton (1998). The categorical statistical measures are defined in a two-class contingency table. Let $\mathrm{N}$ be the total number of cases and a, b, c, d defined for two data sets A and B as follows:

$$
\begin{aligned}
& \mathrm{a}=\text { hits } \\
& \mathrm{b}=\text { misses } \\
& \mathrm{c}=\text { false alarms } \\
& \mathrm{d}=\text { correct negatives } \quad(\text { no } \operatorname{rain}(\mathrm{A}) / \text { no } \operatorname{rain}(\mathrm{B}))
\end{aligned}
$$

From combinations of these four elements, the statistical measures used are defined as follows:

$$
\begin{aligned}
\text { ACCU: accuracy } & =(\mathrm{a}+\mathrm{d}) / \mathrm{N} \text { with } \\
\mathrm{N} & =\mathrm{a}+\mathrm{b}+\mathrm{c}+\mathrm{d} \\
\text { BS: bias score } & =(\mathrm{a}+\mathrm{c}) /(\mathrm{a}+\mathrm{b}) \\
\text { FAR: false alarm rate } & =\mathrm{c} /(\mathrm{a}+\mathrm{c}) \\
\text { robability of detection } & =\mathrm{a} /(\mathrm{a}+\mathrm{b}) \\
\text { TS: threat score } & =\mathrm{a} /(\mathrm{a}+\mathrm{b}+\mathrm{c})
\end{aligned}
$$

POD: probability of detection $=a /(a+b)$

ETS: equitable threat score

$$
=(\mathrm{a}-\mathrm{rnd}) /(\mathrm{a}+\mathrm{b}+\mathrm{c}-\mathrm{rnd})
$$

where $r$ d $=(\mathrm{a}+\mathrm{b}) *(\mathrm{a}+\mathrm{c}) / \mathrm{N}$

$$
\text { OR: odds ratio }=(\mathrm{a} * \mathrm{~d}) /(\mathrm{b} * \mathrm{c})
$$

HK: Hanssen-Kuipers skill score

(Hanssen \& Kuipers 1965) $=a /(a+b)-c /(c+d)$

HSS: Heidke skill score (Heidke 1926)

$$
=\mathrm{POD}-\mathrm{c} /(\mathrm{c}+\mathrm{d})
$$

$$
\begin{aligned}
& =((\mathrm{a}+\mathrm{d})-\mathrm{E}) /(\mathrm{N}-\mathrm{E}) \\
\text { where } \mathrm{E} & =((\mathrm{a}+\mathrm{b}) *(\mathrm{a}+\mathrm{c})+(\mathrm{b}+\mathrm{d}) *(\mathrm{c}+\mathrm{d})) / \mathrm{N}
\end{aligned}
$$


ETS, HK and HSS are commonly used for rainfall verification purposes. Which of them is the most appropriate is still an open issue (Manzato 2005): ETS is sensitive to hits and penalises both misses and false alarms, while HSS measures improvement over random chance. More information on the different scores for satellite-based rainfall can be found online (Ebert 2005).

The study area extends from $15^{\circ} \mathrm{W}$ to $20^{\circ} \mathrm{E}$ (Canary Islands to Italy) and from $30^{\circ} \mathrm{N}$ to $60^{\circ} \mathrm{N}$ (Morocco to Great Britain). The common study period is from 8 to 13 November 2001, and the resolution of the grid for the resampling of rain intensities is $0.25^{\circ}(\sim 28 \mathrm{~km})$ both in latitude and longitude. TRMM and IRE data do not evenly cover the study area, and so the subsequent comparison was conducted only over the available common area. The temporal coincidence was optimal for the two PMW algorithms, because PATER and FDA have the same TMI database, otherwise the temporal offset (time window) was less than $+/-15$ minutes for comparisons with IR (NRL, IRE) and in most cases better than $+/-90$ minutes for comparisons with the independent model data, which have a 3-hourly temporal resolution. Comparisons were performed for single orbits as well as for merged data within $3 \mathrm{~h}$ periods.

\section{Results}

A validation study of the satellite rainfall estimations has been performed for the Algerian flood event using independent intercomparison of different rainfall retrievals, including pure PMW, pure IR, combined $\mathrm{MW} / \mathrm{IR}$ techniques and model results using BOLAM.

The results of this intercomparison are shown in Figures 5-8 for a fixed target date (10 November 2001, 0300 UTC), corresponding to the period of maximum rainfall intensity during the Algerian flood. A complete analysis of the categorical statistics with selected scores of all possible combinations of the above rainfall algorithms within the period 8-13 November 2001 is given in Table 1.

Figure 5 shows three areas of heavy rainfall, one is located west of the Canary Islands, the biggest one west of Algiers $\left(36^{\circ} 46^{\prime} \mathrm{N}, 3^{\circ} 02^{\prime} \mathrm{E}\right)$ and one west of Sicily. The three rain areas coincide very well for both MW algorithms. Also, the strong rain intensities are similar except for the Sicily area. FDA works over land and ocean, PATER exclusively over ocean. The overall correlation coefficient of 0.88 for both PMW algorithms is limited to moderate $\left(1\right.$ to $\left.3 \mathrm{~mm} \mathrm{~h}^{-1}\right)$, high $\left(3\right.$ to $\left.6 \mathrm{~mm} \mathrm{~h}^{-1}\right)$ and very high $\left(>6 \mathrm{~mm} \mathrm{~h}^{-1}\right)$ rain rates. The coherent rain area with low intensities (around $1 \mathrm{~mm} \mathrm{~h}^{-1}$ ) off the north coast of Libya is erroneously detected (Figure 5, top). It is the result of strong desert aerosol, also detected as aerosol fallout in Rome the next day. The rainy speckles over the Atlantic are due to cumulus convective showers within the cold air, which are widely below the minimum detectable threshold of $1 \mathrm{~mm} \mathrm{~h}^{-1}$.

Compared to the PMW techniques, the BOLAM model rainfall forecast shows wide agreement for the strong rain bands (Figure 6). The main rain structure agrees well, with only one heavy rain area being too far west of Sicily. However, the shower pattern over the Atlantic is not well matched and there are many areas with light rain in the model that are not detected with the MW algorithms. These data show a high correlation coefficient (0.83) with FDA, while the overall performance is somewhat less, due to too much light rain in BOLAM.

The two IR-based algorithms, NRL and IRE (Figures 7 and 8), give heavy rain areas over the Mediterranean Sea, but not at the correct position. The Algerian coast, where the maximum precipitation fell, would not be classified as a heavy rain area. The combined MW/IR NRL algorithm performs much better than the pure IR algorithm IRE.

In Table 1, N (the number of compared pairs for the period 8-13 November 2001) differs for each algorithm. The most comprehensive data set is from NRL due to the high repetition rate of METEOSAT. The following abbreviations are used: $\mathrm{B}=\mathrm{BOLAM}$, $\mathrm{F}=\mathrm{FDA}, \mathrm{P}=$ PATER. Extreme values are in bold (maxima) and italic (minima). For each algorithm a summary line is given and all comparisons are summarised in a total line, the last line giving the event occurrences as a percentage.

The accuracy of the different intercomparisons ranges from 0.62 (BOLAM versus IRE), via respectable 0.78 (BOLAM versus FDA), to optimal 0.82 (PATER versus FDA). No bias between PATER and FDA is indicated (score $=1)$, though this is not surprising as they use the same TRMM database. The FDA performs best in terms of accuracy, while the PATER algorithm seems to be nearly bias free in all intercomparisons. The bias score of BOLAM versus both PMW techniques is quite high. This is mainly due to the low rain intensities often present in the model forecasts, which are not detected either with PATER or with FDA, potentially because of the high rain/no-rain threshold. An optimal FAR is obtained with FDA, and POD is best with BOLAM. Consequently, BOLAM has an optimal performance with HK, which depends on POD. Both IR algorithms show their strengths with the scores of HSS, ETS and TS, which are not independent of each other.

As can be seen in Table 1, each algorithm has its own strength, but none of them performs perfectly with all the scores e.g. PATER is generally bias free, but has the worst ETS and HSS. Therefore, it seems to be worthwhile to combine the high temporal resolution of IR with the better rainfall identification performance of 
Table 1. Categorical statistics for different satellite rain retrievals and BOLAM forecasts.

\begin{tabular}{|c|c|c|c|c|c|c|c|c|c|c|c|c|c|c|}
\hline & $\begin{array}{l}\mathrm{N} \\
\text { comp. } \\
\text { pairs }\end{array}$ & $\begin{array}{l}\text { a } \\
\text { hits }\end{array}$ & $\begin{array}{l}\mathrm{b} \\
\text { misses }\end{array}$ & $\begin{array}{l}\text { c } \\
\text { false } \\
\text { alarms }\end{array}$ & $\begin{array}{l}\mathrm{d} \\
\text { correct } \\
\text { negatives }\end{array}$ & $\begin{array}{l}\text { ACCU } \\
\text { best }=1\end{array}$ & $\begin{array}{l}\text { BS } \\
\text { best }=1\end{array}$ & $\begin{array}{l}\text { FAR } \\
\text { best }=0\end{array}$ & $\begin{array}{l}\text { POD } \\
\text { best }=1\end{array}$ & $\begin{array}{l}\mathrm{OR} \\
\text { best }=\mathrm{N}\end{array}$ & $\begin{array}{l}\mathrm{HK} \\
\text { best }=1\end{array}$ & $\begin{array}{l}\text { HSS } \\
\text { best }=1\end{array}$ & $\begin{array}{l}\text { ETS } \\
\text { best }=1\end{array}$ & $\begin{array}{l}\text { TS } \\
\text { best }=1\end{array}$ \\
\hline$\overline{P \text { vs. F }}$ & 3352 & 84 & 298 & 298 & 2672 & 0.82 & 1 & 0.78 & 0.22 & 2.53 & 0.12 & 0.12 & 0.06 & 0.12 \\
\hline P vs. B & 8354 & 409 & 1761 & 993 & 5191 & 0.67 & 0.65 & 0.71 & 0.19 & 1.21 & 0.03 & 0.03 & 0.02 & 0.13 \\
\hline P vs. NRL & 14619 & 482 & 2091 & 2222 & 9824 & 0.7 & 1.05 & 0.82 & 0.19 & 1.02 & 0 & 0 & 0 & 0.1 \\
\hline P vs. IRE & 2593 & 187 & 431 & 519 & 1456 & 0.63 & 1.14 & 0.74 & 0.3 & 1.22 & 0.04 & 0.04 & 0.02 & 0.16 \\
\hline PATER & 28918 & 1162 & 4581 & 4032 & 19143 & 0.7 & 0.9 & 0.78 & 0.2 & 1.2 & 0.03 & 0.03 & 0.01 & 0.12 \\
\hline F vs. P & 3352 & 84 & 298 & 298 & 2672 & 0.82 & 1 & 0.78 & 0.22 & 2.52 & 0.12 & 0.12 & 0.06 & 0.12 \\
\hline F vs. B & 6127 & 686 & 1121 & 257 & 4063 & 0.78 & 0.52 & 0.27 & 0.38 & 9.67 & 0.32 & 0.37 & 0.23 & 0.33 \\
\hline F vs. NRL & 7143 & 357 & 1086 & 279 & 5421 & 0.81 & 0.44 & 0.44 & 0.25 & 6.39 & 0.2 & 0.25 & 0.14 & 0.21 \\
\hline F vs. IRE & 930 & 116 & 217 & 73 & 524 & 0.69 & 0.57 & 0.39 & 0.35 & 3.84 & 0.23 & 0.25 & 0.14 & 0.29 \\
\hline FDA & 17552 & 1243 & 2722 & 907 & 12680 & 0.79 & 0.54 & 0.42 & 0.31 & 6.38 & 0.25 & 0.29 & 0.17 & 0.26 \\
\hline $\mathrm{B}$ vs. $\mathrm{P}$ & 8354 & 409 & 993 & 1761 & 5191 & 0.67 & 1.55 & 0.81 & 0.29 & 1.21 & 0.04 & 0.03 & 0.02 & 0.13 \\
\hline B vs. F & 6127 & 686 & 257 & 1121 & 4063 & 0.78 & 1.92 & 0.62 & 0.73 & 9.67 & 0.51 & 0.37 & 0.23 & 0.33 \\
\hline B vs. NRL & 13880 & 1374 & 1846 & 1513 & 9147 & 0.76 & 0.9 & 0.52 & 0.43 & 4.5 & 0.28 & 0.3 & 0.17 & 0.29 \\
\hline B vs. IRE & 3777 & 842 & 377 & 1079 & 1479 & 0.61 & 1.58 & 0.56 & 0.69 & 3.06 & 0.27 & 0.23 & 0.13 & 0.37 \\
\hline BOLAM & 32138 & 3311 & 3473 & 5474 & 19880 & 0.72 & 1.29 & 0.62 & 0.49 & 3.46 & 0.27 & 0.25 & 0.14 & 0.27 \\
\hline NRL vs. P & 14619 & 482 & 2222 & 2091 & 9824 & 0.7 & 0.95 & 0.81 & 0.18 & 1.02 & 0 & 0 & 0 & 0.1 \\
\hline NRL vs. F & 7142 & 357 & 279 & 1086 & 5421 & 0.81 & 2.27 & 0.75 & 0.56 & 6.39 & 0.39 & 0.25 & 0.14 & 0.21 \\
\hline NRL vs. B & 13880 & 1374 & 1513 & 1846 & 9147 & 0.76 & 1.12 & 0.57 & 0.48 & 4.5 & 0.31 & 0.3 & 0.17 & 0.29 \\
\hline NRL vs. IRE & 6320 & 1302 & 702 & 986 & 3324 & 0.73 & 1.14 & 0.43 & 0.65 & 6.25 & 0.42 & 0.41 & 0.25 & 0.44 \\
\hline NRL & 41961 & 3516 & 4715 & 6008 & 27716 & 0.74 & 1.16 & 0.63 & 0.43 & 3.44 & 0.25 & 0.23 & 0.13 & 0.25 \\
\hline IRE vs. P & 2593 & 187 & 519 & 431 & 1456 & 0.63 & 0.88 & 0.7 & 0.26 & 1.22 & 0.04 & 0.04 & 0.02 & 0.16 \\
\hline IRE vs. F & 930 & 116 & 73 & 217 & 524 & 0.69 & 1.76 & 0.65 & 0.61 & 3.84 & 0.32 & 0.25 & 0.14 & 0.29 \\
\hline IRE vs. B & 3777 & 842 & 1079 & 377 & 1479 & 0.61 & 0.63 & 0.31 & 0.44 & 3.06 & 0.24 & 0.23 & 0.13 & 0.37 \\
\hline IRE vs. NRL & 6314 & 1302 & 986 & 702 & 3324 & 0.73 & 0.88 & 0.35 & 0.57 & 6.26 & 0.39 & 0.41 & 0.25 & 0.44 \\
\hline IRE & 13614 & 2447 & 2657 & 1727 & 6783 & 0.68 & 0.82 & 0.41 & 0.48 & 3.62 & 0.28 & 0.29 & 0.17 & 0.36 \\
\hline total & 134178 & 11678 & 18149 & 18149 & 86202 & 0.73 & 1 & 0.61 & 0.39 & 3.06 & 0.22 & 0.22 & 0.12 & 0.24 \\
\hline total in $\%$ & 100 & 9 & 14 & 14 & 64 & & & & & & & & & \\
\hline
\end{tabular}

Data rely on 8-13 November 2001 of the western Mediterranean region.

$\mathrm{B}=\mathrm{BOLAM}, \mathrm{F}=\mathrm{FDA}, \mathrm{P}=$ PATER. Maximum values per column are in bold, minimum in italic. For each algorithm a summary line is given and all comparisons are summarised in a total line, the last line gives the event occurrences as percentage. 
MW techniques for monitoring rainfall from space. The NRL algorithm or the now available TRMM 3B42RT products belong to this category. The low MW pixel resolution makes a $0.25^{\circ}(\sim 28 \mathrm{~km})$ latitude-longitude grid appropriate, but better spatial resolution is required by the users.

The overall FAR is about 0.61 , the POD is only 0.39 , and misses and false alarms are in the order of $14 \%$, showing that there is still a highly visible potential for the development of each algorithm. At the moment, no single algorithm is able to characterise the rainfall situation satisfactorily, but a combination of different approaches, bringing together the qualities of each algorithm, seems to be the best way to tackle the problem of rainfall estimation and shows considerable promise. Problems are still present in the detection of light rain in the MW retrievals and in following the development of storms. Moreover, the models suffer to some extent from location errors of the forecasted rain areas, depending on the time intervals between programme start and valid time, and the IR methods have difficulty with short time accumulations and instantaneous rain rates. The accuracy of all comparisons together has a mean value of 0.73 on a small-scale grid of $\sim 28 \mathrm{~km}$. Nevertheless, the accuracy is dependent on the rain/no-rain threshold, the minimum detectable rain rate of the PMW algorithms.

Note, that even in this heavy rain event, only $9 \%$ are hits (rain/rain), whereas $64 \%$ are correct negatives (no-rain/no-rain), the latter dominate the statistics of accuracy, OR, HK, ETS and HSS.

\section{Conclusions}

A heavy rainfall episode characterised by intense convection - the Algerian flood - in November 2001 was selected for a validation analysis of different satellite rainfall algorithms representing MW, IR or combined MW/IR retrievals and forecasts of the mesoscale BOLAM model. The variety of multi-sensor rainfall estimations applied to the same event is one of the strengths of the EURAINSAT project that brought these different approaches together. The rainfall data were uniquely gridded at $0.25^{\circ}(\sim 28 \mathrm{~km})$ latitudelongitude in a common area over south-western Europe. Categorical statistics based on dichotomous data (rain/no rain) were generally used because the correlation coefficient for two different rainfall data sets has already been shown to be dependent on the choice of the grid size (Turk et al. 2002).

The maximum correlation coefficient is reached in this study on the $0.25^{\circ}$ grid for both PMW techniques 0.88 for PATER versus FDA (orbit 22741). The best correlation for the model BOLAM versus PATER reaches 0.83 (orbit 22742). Generally, the correlation coefficient is not thought to be the most appropriate measure in rain algorithm intercomparisons because the frequency distribution of rain is a very skewed one and not a Gaussian.

The accuracy varies for the same data sets by changing the grid size, too. Threshold tests with PATER and FDA have further shown how crucially dependent the accuracy results are on the minimum detectable rain rate (Kästner 2003). A practicable threshold seems to be reached when the sum of hits and misses is firmly above the false alarms. Since the rainy pixels are usually in the minority, the statistics are dominated by the correct negatives and not by the hits. Therefore, the use of entity-based methods like contiguous rain area verification may give further insights into algorithm performances (Ebert \& McBride 2000).

Special interest was focused on the PATER algorithm that uses active PR and passive TMI data of the TRMM satellite. The PATER retrieval is crucially dependent on the forward 3-D cloud model calculations. There is a need for better and more comprehensive cloud models that cover the whole spectrum of natural clouds, particularly clouds with moderate and light rain (intensities below $1 \mathrm{~mm} \mathrm{~h}^{-1}$ ).

Both PMW retrievals, PATER and FDA, rely on the same TMI orbit data and so it was expected that their comparison would result in a rather similar rainfall area and intensity, disregarding low rain events due to assumptions in the retrievals. Both algorithms are assessed to be of equal quality in a heavy rainfall event, except the restriction of PATER to ocean surfaces only. The FDA has optimal accuracy values and PATER is almost bias free. The most successful comparison of pure PMW with other techniques was against the BOLAM model output followed by the NRL blended MW/IR technique, both performing better than the pure IR technique.

A general outcome was that each algorithm has its own strength and there is not a single algorithm with optimal performance. The combination of different retrievals seems to be better suited to tackling the rain detection and estimation problem. The results suggest a combination of IR and PMW rainfall estimates so that the strength of both, the well-known rain physics of the MW channels and the high temporal resolution of IR algorithms, improves the precipitation estimates from satellite data. A better temporal sampling is necessary because data from low orbiting satellites are not well suited to follow the development of a storm event.

Moreover, small-scale convective showers in cold air generally seem to be difficult to detect for the mesoscale hydrostatic models (area) as well as for the MW algorithms (intensity), but the strong and heavy frontal rain bands present almost no problem for MW-based or model-based detection. With a mean accuracy of 0.73 at 
a $28-\mathrm{km}$ scale this is an encouraging prospect and paves the way for satellite rainfall products being assimilated into mesoscale models for more precise flood forecasts and heavy rain events.

New observations from satellite missions are already available from METEOSAT Second Generation (MSG), which provides an image frequency of 15 minutes, thereby enhancing the use of life history techniques for convective systems. The launch of new MW sensors, like the Global Precipitation Measurement (GPM) (Flaming 2002) will provide three-hourly data that could be used for the calibration of the IR datasets. The GPM scientific team acknowledged the value of high frequency channels for the detection of light rain and snow, especially over land (Bidwell et al. 2005), and NASA has recently approved the incorporation of high frequency capability on GPM instruments.

\section{Acknowledgements}

This research was funded by the EURAINSAT project, a shared-cost project (contract EVG1-2000-00030), cofunded by the Research DG of the European Commission within the RTD activities of a generic nature of the Environment and Sustainable Development subprogramme (5th Framework Programme). We wish to thank C. Kidd of the School of Geography, University of Birmingham, UK and Francesco Meneguzzo of the Climate Observatory, Institute of Biometeorology, National Research Council, Florence, Italy, for their provision of rain data.

\section{References}

Adler, R. F., Kidd, C., Petty, G., Morrissey, M. \& Goodman, M. (2001) Intercomparison of global precipitation products: The third precipitation intercomparison project (PIP-3). Bull. Am. Meteorol. Soc. 82: 1377-1396.

Adler, R. F., Huffman, G. \& Bolvin, D. (2002) TRMM and GPCP initial cross-comparison. GEWEX News 12 (Nov): $5-6$.

Barrett, E. C. (1970) The estimation of monthly rainfall from satellite data. Mon. Weather Rev. 98: 322-327.

Barrett, E. C. \& Martin, D. W. (1981) The Use of Satellite Data in Rainfall Monitoring. London: Academic Press, 340 pp.

Bauer, P. (2001) Over-ocean rainfall retrieval from multisensor data of the Tropical Rainfall Measuring Mission. Part I: Design and evaluation of inversion databases. J. Atmos. Oceanic Technol. 18: 1315-1330.

Bauer, P., Burose, D. \& Schulz, J. (2000) Rain detection over land surfaces using passive microwave satellite data. ECMWF Technical Memo. No. 330, Reading, UK.

Bauer, P., Amayenc, P., Kummerow, C. D. \& Smith, E. A. (2001) Over-ocean rainfall retrieval from multisensor data of the Tropical Rainfall Measuring Mission. Part II: Algorithm implementation. J. Atmos. Oceanic Technol. 18: 18381855

Bidwell, S. W., Flaming, G. M., Durning, J. F. \& Smith, E. A. (2005) The Global Precipitation Measurement (GPM) Microwave Imager (GMI) instrument: role, performance and status. In: Proc. IGARSS 2005, Seoul, Korea, 25-29 July.

Bolle, H.-J. (ed.) (2003) Mediterranean Climate - Variablility and Trends. Berlin: Springer, $372 \mathrm{pp}$.

Buzzi, A., D’Isidoro, M. \& Davolio, S. (2003) A case study of an orographic cyclone formation south of the Alps during the MAP-SOP. Q. J. R. Meteorol. Soc. 129: 1795-1818.

Calheiros, R. V. \& Zawadzki, I. (1987) Reflectivity rain-rate relationship for radar hydrology and Brazil. J. Clim. Appl. Meteorol. 26: 118-132.

Davolio, S. \& Buzzi, A. (2004) A nudging scheme for the assimilation of precipitation data into a mesoscale model. Wea. Forecasting 19: 855-871.

Ebert, E. E. (1996) Results of the 3rd Algorithm Intercomparison Project (AIP-3) of the Global Precipitation Climatology Project (GPCP). Research Report 55, Bureau of Meteorology Research Centre, Melbourne, Australia, 204 pp.

Ebert, E. E. (2005) http://www.bom.gov.au/bmrc/wefor/staff/ eee/verif/verif_web_page.html last updated: 5 December 2005.

Ebert, E. E. \& McBride, J. L. (2000) Verification of precipitation in weather systems: determination of systematic errors. J. Hydrol. 239: 179-202.

Ebert, E. E. \& Manton, M. J. (1998) Performance of satellite rainfall estimation algorithms during TOGA COARE. J. Atmos. Sci. 55: 1537-1557.

Ebert, E. E., Manton, M. J., Arkin, P. A., Allam, R. J., Holpin, G. E. \& Gruber, A. (1996) Results from the GPCP Algorithm Intercomparison Program (AIP). Bull. Am. Meteorol. Soc. 77: 2875-2887.

Ferraro, R. R. (1997) Special sensor microwave imager derived global rainfall estimates for climatological applications. J. Geophys. Res. 102 (D14): 16715-16735.

Ferraro, R. R. \& Marks, G. F. (1995) The development of SSM/I rain-rate retrieval algorithms using ground-based radar measurements. J. Atmos. Ocean. Tech. 12: 755-770.

Flaming, G. M. (2002) Requirements for global precipitation measurement. In: Proc. IGARSS 2002, Vol. 1, Toronto, Canada, 24-28 June, IEEE: 269-271.

Georgelin, M. P., Bougeault, P., Black, T., Brzovic, N., Buzzi, A., Calvo, J., Cassé, V., Desgagné, M., El-Khatib, R., Geleyn, J. F., Holt, T., Hong, S.-Y., Kato, T., Katzfey, J., Kurihara, K., Lacroix, B., Lalaurette, F., Lemaitre, Y., Mailhot, J., Majewsky, D., Malguzzi, P., Masson, V., McGregor, J., Minguzzi, E., Paccagnella, T. \& Wilson, C. (2000) The second COMPARE exercise: a model intercomparison using a case of a typical mesoscale orographic flow, the PYREX IOP3. Q. J. R. Meteorol. Soc. 126: 991-1030.

Grose, A., Smith, E. A., Chung, H.-S., Ou, M. L., Sohn, B. J. \& Turk, F. J. (2002) Possibilities and limitations for QPF using nowcasting methods with infrared geosynchronous satellite imagery. J. Appl. Meteorol. 41: 763-785.

Hanssen, A. W. \& Kuipers, W. J. A. (1965) On the relationship between the frequency of rain and various meteorological parameters. Kon. Neder. Meteorol. Inst. Meded. Verhand. 81: 2-15.

Hartman, D. L. (1994) Global Physical Climatology. San Diego and London: Academic Press, 411 pp.

Heidke, P. (1926) Berechnung des Erfolges und der Güte der Windstärkevorhersagen im Sturmwarnungsdienst. Geogr. Ann. 8: 301-349.

Kästner, M. (2003) Intercomparison of precipitation estimations using TRMM microwave data and independent 
data. In: Proc. 3rd GPM Workshop 'Consolidating the Concept', Noordwijk, The Netherlands, 24-26 June 2003, AP-5.

Kästner, M. \& Erbertseder, T. (2002) Estimation of precipitation using TRMM TMI and PR data of the Algerian flood event in November 2001. In: Proc. 2002 EUMETSAT Meteorological Satellite Data Users' Conference, 26 September 2002, Dublin, Ireland, EUM P 36: 286-292.

Kain, J. S. \& Fritsch, J. M. (1990) A one-dimensional entraining/detraining plume model and its application in convective parameterization. J. Atmos. Sci. 47: 2784-2802.

Kidd, C., Kniveton, D., Todd, M. \& Bellerby, T. (2003) Satellite rainfall estimation using a combined passive microwave and infrared algorithm. J. Hydrometeorol. 4: 1088-1104.

Kidder, S. Q. \& Vonder Haar, T. H. (1995) Satellite Meteorology: An Introduction. San Diego and London: Academic Press, 466 pp.

Kummerow, C., Barnes, W., Kozu, T., Shiue, J. \& Simpson, J. (1998) The tropical rainfall measuring mission (TRMM) sensor package. J. Atmos. Ocean Tech. 15: 809-816.

Levizzani, V. (2003) Satellite rainfall estimations: new perspectives for meteorology and climate from the EURAINSAT project. Ann. Geophys. 46: 363-372.

Levizzani, V., Schmetz, J., Lutz, H. J., Kerkmann, J., Alberoni, P. P. \& Cervino, M. (2001) Precipitation estimations from geostationary orbit and prospects for METEOSAT Second Generation. Meteorol. Appl. 8: 23-41.

Levizzani, V., Bauer, P., \& Turk, F. J. (eds.) (2006) Measuring Precipitation from Space: EURAINSAT and the Future. Berlin: Springer, in press.

Louis, J. F., Tiedtke, M. \& Geleyn, J.-F. (1981) A short history of operational PBL parameterization at ECMWF. In: Proc. ECMWF Workshop on PBL Parameterization, Reading (UK), November 1981: 59-79.

Malguzzi, P. \& Tartaglione, N. (1999) An economical second order advection scheme for explicit numerical weather prediction. Q. J. R. Meteorol. Soc. 125: 2291-2304.

Manzato, A. (2005) An Odds ratio parameterization for ROC diagram and skill score indices. Weather Forecast. 20: 918930.

Oh, H. J., Sohn, B. J., Smith, E. A., Turk, F. J., Seo, A. S. \& Chung, H. S. (2002) Validating infrared-based rainfall retrieval algorithms with 1-minute spatially dense raingauge measurements over the Korean peninsula. Meteorol. Atmos. Phys. 81: 273-287.

Pinori, S., Adamo, C., Di Michele, S., Dietrich, S., Mugnai, A., Tassa, A., Tripoli, G. J. \& Smith, E. A. (2002) Satellite observations of heavy rain producing storms over the Mediterranean area. In: Proc. of the 4th EGS Plinius Conference on Mediterranean Storms, Mallorca, Spain, October 2002.

Prigent, C. (2006a) Microwave emissivity in arid regions, what can we learn from satellite observations? In: C. Mätzler, (ed.), Radiative Transfer Models for Microwave Radiometry, in press, ch. 4.5 .
Prigent, C. (2006b) Passive microwave emissivity in vegetated regions as directly calculated from satellite observations. In: C. Mätzler (ed.), Radiative Transfer Models for Microwave Radiometry, in press, ch. 4.6.

Ritter, B. \& Geleyn, J. F. (1992) A comprehensive radiation scheme for numerical weather prediction models with potential applications in climate simulations. Mon. Weather Rev. 120: 303-325.

Rudolf, B., Hauschild, H., Rüth, W. \& Schneider, U. (1996) Comparison of rain gauge analyses, satellite-based precipitation estimates and forecast model results. $A d v$. Space Res. 18: 53-62.

Schultz, P. (1995) An explicit cloud physics parameterization for operational numerical weather prediction. Mon. Weather Rev. 123: 3331-3343.

Schumacher, C. \& Houze, R. A. (2000) Comparison of Radar Data from the TRMM Satellite and Kwajalein Oceanic Validation Site. J. Appl. Meteorol. 39: 2151-2164.

Spencer, P. L. \& Stensrud, D. J. (1998) Simulating flash flood events: importance of the subgrid representation of the convection. Mon. Weather Rev. 126: 2884-2912.

Tapiador, F. (2002) A new algorithm to generate global rainfall rates from satellite infrared imagery. Revista de Teledeteccion 18: 57-61.

Thomas, W., Baier, F., Erbertseder, T. \& Kästner, M. (2003) Analysis of the Algerian severe weather event in November 2001 and its impact on ozone and nitrogen dioxide distributions. Tellus B 55B: 993-1006.

Todd, M. C. \& Bailey, J. O. (1995) Estimates of rainfall over the UK and surrounding seas from SSM/I using polarized corrected temperature algorithm. J. Appl. Meteorol. 34: 1254-1265.

Tripoli, G. J., Medaglia, C. M., Dietrich, S., Mugnai, A., Panegrossi, G., Pinori, S. \& Smith, E. A. (2005) The 910 November 2001 Algerian flood: a numerical study. Bull. Am. Meteorol. Soc. 86: 1229-1235.

Turk, F. J., Rohaly, G., Hawkins, J., Smith, E. A., Marzano, F. S., Mugnai, A. \& Levizzani, V. (2000a) Meteorological applications of precipitation estimation from combined SSM/I, TRMM and geostationary satellite data. In: P. Pampaloni and S. Paloscia (eds.) Microwave Radiometry and Remote Sensing of the Earth's Surface and Atmosphere, Utrecht: VSP Int. Sci. Publisher, 353363.

Turk, F. J., Rohaly, G., Hawkins, J., Smith, E. A., Marzano, F. S., Mugnai, A. \& Levizzani, V. (2000b) Analysis and assimilation of rainfall from blended SSMI, TRMM and geostationary satellite data. In: Proc. 10th AMS Conf. Sat. Meteorol. E Ocean. 9-14 January, Long Beach, CA., 6669.

Turk, F. J., Ebert, E. E., Oh, H. J., Sohn, B. J., Levizzani, V., Smith, E. A. \& Ferraro, R. (2002) Validation of an operational global precipitation analysis at short time scales. In: Proc. 1st Workshop Int. Precip. Working Group (IPWG), Madrid, Spain, 23-27 Sept. 2002. 